\title{
Pesquisa em empreendedorismo: a produção científica francófona em perspectiva
}

\author{
ALEX FernANDO BORges ${ }^{1}$ \\ ALESSANDRO GOMES ENOQUE ${ }^{1}$
}

${ }^{1}$ Universidade Federal de Uberlândia (UFU) / Faculdade de AdMinistração, CIÊNCIAS Contábeis, Engenharia de Produção E SERVIÇO SOCIAL, ITUIUTABA - MG, BRASIL

\begin{abstract}
Resumo
O objetivo do presente artigo consistiu em revisar a literatura em empreendedorismo publicada em língua francesa. Para tanto, estruturou-se uma revisão de escopo dos artigos listados em periódicos relevantes para o contexto francófono da produção científica em empreendedorismo (LASCH e YAMI, 2008): Management International; Revue Française de Gestion; e Revue Internationale PME, com base nos critérios de inclusão e exclusão detalhados e estabelecidos na metodologia do mapeamento. Isso possibilitou a categorização de 166 artigos que abordam a temática, publicados entre 2006 e 2019. Os textos foram analisados e categorizados em torno da distribuição dos artigos entre os periódicos, sua distribuição anual, principais temas de pesquisa, tipo de abordagem, escolhas metodológicas e principais autores do campo. Os resultados indicaram predominância de temáticas específicas na produção francófona, como: fomento ao empreendedorismo, intraempreendedorismo, processo empreendedor e oportunidades, empreendedorismo feminino, finanças, educação empreendedora, perfil e comportamento empreendedor, intenção empreendedora, motivações ao empreendedorismo e empreendedorismo social. Houve predominância de estudos teórico-empíricos, de natureza qualitativa, mas também com espaço significativo para ensaios teóricos sobre o tema. Verificou-se, ainda, a participação de um conjunto de autores centrais que produzem, pesquisam e disseminam resultados de suas investigações sobre empreendedorismo. Com isso, nota-se a constituição de um campo de pesquisas francófono em empreendedorismo plural e multifacetado, que apresenta possibilidades e alternativas teórico-metodológicas para a realização de estudos e investigações sobre o fenômeno empreendedor.
\end{abstract}

Palavras-chave: Empreendedorismo. Empreendedor. Revisão de literatura. França. Canadá.

\section{Entrepreneurship research: the French literature in perspective}

\begin{abstract}
This article reviews entrepreneurship literature available in French. We reviewed articles published in the following French journals: Management International; Revue Française de Gestion; and Revue Internationale PME, considered relevant venues for entrepreneurship research (LASCH and YAMI, 2008), and based on inclusion and exclusion criteria established and detailed in the methodology. This allowed us to identify 166 entrepreneurship articles published in French from 2006 to 2019. To analyze and categorize these studies, we highlighted their presence in the aforementioned journals, the number of articles published per year, their main research topics, their methodological approach and techniques, and the most prominent researchers. The results show the predominance of specific topics such as public policies and support to entrepreneurship, intrapreneurship, entrepreneurial process and opportunities, women entrepreneurship, finance, entrepreneurial education, entrepreneurial behavior, entrepreneurial intention, entrepreneurs' motivations, and social entrepreneurship. Theoretical-empirical, qualitative studies are prevailing, but there is also room for theoretical papers on entrepreneurship. Finally, several researchers contribute to the field, investigating, writing, and publishing articles on entrepreneurship. In conclusion, we observed the formation of a plural, multifaceted francophone entrepreneurship field that presents theoretical-methodological possibilities and alternatives for the development of research on entrepreneurial phenomena.
\end{abstract}

Keywords: Entrepreneurship. Entrepreneur. Literature review. France. Canada.

\section{Investigación sobre emprendimiento: la producción científica francófona en perspectiva}

\section{Resumen}

El propósito de este artículo consistió en presentar una revisión de la literatura sobre emprendimiento publicada en francés. Para ello, se efectuó una revisión de los artículos enumerados en revistas relevantes para el contexto francófono de la producción científica sobre emprendimiento (LASH y YAMI, 2008): Management International; Revue Française de Gestion; y Revue Internationale PME, con base en los criterios de inclusión y exclusión detallados y establecidos en la metodología del mapeo. Esto permitió la categorización de 166 artículos que abordan el tema, publicados entre 2006 y 2019. Los textos se analizaron y categorizaron en torno a la distribución de artículos entre las revistas, su distribución anual, principales temas de investigación, tipo de abordaje, opciones metodológicas y principales autores del campo. Las evidencias muestran el predominio de temas de investigación específicos como: políticas públicas y apoyo al emprendimiento, intraemprendimiento, proceso emprendedor y oportunidades, emprendimiento femenino, finanzas, educación emprendedora, perfil y comportamiento emprendedor, intención emprendedora, motivaciones al emprendimiento y emprendimiento social. Predominaron los estudios teórico-empíricos y cualitativos, pero también con espacio significativo para ensayos teóricos sobre el tema. Asimismo, se verificó la formación de un campo de investigaciones sobre emprendimiento francófono plural y multifacético, que presenta posibilidades y alternativas teóricas y metodológicas para la realización de estudios e investigaciones sobre el fenómeno emprendedor.

Palabras clave: Emprendimiento. Emprendedor. Revisión de la literatura. Francia. Canadá. 


\section{INTRODUÇÃO}

Atualmente, verificam-se diversas iniciativas para a delimitação do escopo e da abrangência do campo de estudos em empreendedorismo (LOPES e LIMA, 2019; SHEPHERD, WENNBERG, SUDDABY et al., 2019). A área apresenta um caráter multidisciplinar, sendo marcada pela influência de diferentes disciplinas (TURCAN e FRASER, 2018), abordagens teórico-metodológicas (MCDONALD, GAN, FRASER et al., 2015; OLIVEIRA JUNIOR, GATTAZ, BERNADES et al., 2018; VALE, 2014) e orientações ontológicas e epistemológicas diversas (ALVAREZ e BARNEY, 2010; HJORTH, 2015). Nesse cenário, há espaço para estudos que objetivem mapear a produção científica sobre empreendedorismo, problematizando as especificidades da literatura sobre o tema, como os tópicos centrais de investigação (OLIVEIRA JUNIOR, GATTAZ, BERNADES et al., 2018), os principais métodos de pesquisa (MCDONALD, GAN, FRASER et al., 2015), os principais pesquisadores da área (TEIXEIRA, 2011), as análises de citações e cocitações (MEYER, LIBAERS, THIJS et al., 2014) e a evolução, a tendência e as agendas para o futuro do campo (CLARK e HARRISON, 2019; FAYOLLE, 2014; SHEPHERD, WENNBERG, SUDDABY et al., 2019). Tais elementos permitem problematizar a pesquisa e a produção científica sobre empreendedorismo, revelando sua relevância e sua dinâmica, bem como sua natureza científica e os principais desafios da área (WIKLUND, WRIGHT e ZAHRA, 2019).

A produção científica em empreendedorismo também tem sido revisada sob o ponto de vista da formação e da estruturação do campo em diferentes países, dando relevo às particularidades da literatura em uma perspectiva regional. Uma fonte relevante de produção e disseminação de conhecimento em empreendedorismo encontra destaque nos países francófonos, como França e Canadá. Com efeito, a França é comumente caracterizada como a origem do termo "empreendedor", que remonta ao século XVI (KIZABA, 2006; MARCHESNAY, 2011). No entanto, a temática é analisada, do ponto de vista acadêmico, de forma relativamente recente nesse contexto, sendo que as primeiras publicações na área de gestão surgiram entre o fim da década de 1980 e o início da década de 1990. As principais associações científicas sobre o tema-Association Internationale de Recherche en Entrepreneuriat et PME (AIREPME) e Academie de l'Entrepreneuriat (AE) - datam, respectivamente, de 1996 e 1998. Já a primeira revista especializada - Revue Internationale P. M. E. - teve sua edição inicial publicada em 1988. Esses fatos revelam a existência de um campo de estudos relativamente emergente e que se encontra ainda em formação e em constante restruturação (FAYOLLE, 2011; MARCHESNAY, 2008).

De fato, a literatura francófona em empreendedorismo tem sido considerada, por autores como Fayolle (2011) e Marchesnay (2011), como uma fonte de natureza secundária em relação ao mainstream internacional do campo de estudos, dadas as barreiras e limitações impostas pelo idioma e pela prevalência natural de estudos e produção científica publicada em língua inglesa, com maior difusão internacional e maior legitimidade na área. Não obstante, Marchesnay (2008) ressalta que existe uma busca, no contexto francófono, pelo estabelecimento de uma visão original de empreendedorismo, a partir da elaboração de concepções teórico-metodológicas alternativas à análise das problemáticas associadas à manifestação desse fenômeno. Isso inclui, por exemplo, uma concentração em investigações qualitativas e exploratórias, com enfoques teóricos mais subjetivos e influenciados em grande parte por escolas interpretativistas, construcionistas, construtivistas e estruturalistas e com grande variedade de objetos estudados e de métodos e técnicas de pesquisa utilizados (JULIEN e RAYMOND, 2008; KIZABA, 2006; LASCH e YAMI, 2008).

Assim, torna-se relevante colocar em perspectiva a produção francófona em empreendedorismo, identificando seus possíveis padrões, tendências e lacunas. Nesse cenário, a pergunta colocada por Gartner (1990) - what are we talking about when we talk about entrepreneurship? - pode também ser aplicada ao contexto da pesquisa francófona em empreendedorismo, abrindo espaço para a questão que norteia a realização deste trabalho: quais são as particularidades da produção científica em empreendedorismo publicada em língua francesa? Para responder a tal questionamento, o objetivo do artigo consiste em revisar a literatura em empreendedorismo publicada em língua francesa, com base na abordagem de revisão de escopo da literatura. Para tanto, efetuou-se um levantamento dos artigos divulgados nos periódicos Management International (MI), Revue Française de Gestion (RFG) e Revue Internationale P. M. E. (RIPME). Estas revistas, selecionadas com base em critérios de inclusão e exclusão detalhados e estabelecidos na seção metodológica da presente revisão de escopo, são consideradas como meios de divulgação relevantes para a produção científica francófona acerca do fenômeno empreendedor, sobretudo por darem abertura editorial à temática - como nos casos das revistas generalistas $M I$ e $R F G$ - e por terem relações com associações científicas voltadas para o tema - no caso da RIPME (FAYOLLE, 2011, 2017; LASCH e YAMI, 2008; MARCHESNAY, 2008, 2011). A partir disso, a técnica de revisão de escopo da literatura viabilizou a identificação e a categorização de 166 artigos que abordam a temática do empreendedorismo, publicados entre 2006 e 2019. Com base nisso, o mapeamento foi 
estruturado e orientado para possibilitar a análise de aspectos centrais vinculados a essa produção. Buscou-se, com isso, elencar particularidades da publicação francófona, destacando suas possíveis contribuições para o campo de pesquisas em empreendedorismo no Brasil.

\section{Empreendedorismo: pesquisa e produção científica}

O fenômeno do empreendedorismo envolve um conjunto de fatos e situações que se associam à prática de empreendedores, que contribuem para a compreensão da dinâmica e das especificidades de seus negócios. Gartner (1990) ressalta que, quando se fala em empreendedorismo, carrega-se um amplo conjunto de crenças e pressupostos sobre aquilo que constitui esse fenômeno, sua delimitação conceitual e suas possibilidades de manifestação.

Com efeito, a temática pode ser definida a partir de perspectivas diversas, que carregam consigo uma vinculação de origem, envolvendo a relação entre empreendedorismo (fenômeno) e empreendedor (agente) (GARTNER, 2012). Com base nesse entendimento, cada corrente de pensamento da área apresenta uma definição mais ou menos central para a adjetivação do referido fenômeno. Em uma perspectiva comportamental, o empreendedorismo tem sido considerado o objeto de decisões e ações de um empreendedor, dotado de um perfil e um comportamento particulares, marcados por traços de personalidade que diferenciam esse indivíduo de outros na economia e na sociedade (FILION, 1999). Em uma perspectiva econômica, o fenômeno empreendedor pode ser compreendido a partir da inovação, envolvendo a atuação de indivíduos que agem de forma independente ou no âmbito de organizações já estabelecidas, introduzindo novos produtos, serviços, processos e tecnologias no mercado (CARLSSON, BRAUNERHJELM, MCKELVEY et al., 2013). Em uma perspectiva processual, o empreendedorismo é definido a partir da presença de oportunidades lucrativas e da existência de indivíduos dispostos a identificá-las e explorá-las. Essa linha de pensamento baseia-se na visualização do referido fenômeno como resultado de um processo empreendedor, devidamente organizado em torno da criação e/ou da identificação de oportunidades de negócio (SHANE e VENKATARAMAN, 2000). Por fim, em uma perspectiva organizacional, o empreendedorismo passa a ser visualizado como a criação de organizações, movimento estruturado com base em processos de emergência, inovação e transformação de empreendimentos diversos (GARTNER e BRUSH, 2016).

Nesse cenário, marcado por uma profusão de definições de empreendedorismo e empreendedor, cabe considerar possíveis diferenças conceituais relevantes. A produção científica norte-americana, frequentemente considerada como referência na área, é responsável pela geração e pela disseminação de conceitos em nível internacional, sendo a origem de vertentes como a comportamental e a processual (MEYER, LIBAERS, THIJS et al., 2014). Por seu turno, a vertente econômica foi originalmente desenvolvida no âmbito das escolas alemãs e austríacas de pensamento em empreendedorismo, relacionando o referido fenômeno à noção de inovação e à ideia de desenvolvimento econômico (SCHMUDE, WELTER e HEUMANN, 2008). Já a vertente organizacional possui raízes associadas a um contexto europeu, com elaborações e fundamentações teóricas observadas nos trabalhos de autores oriundos do Reino Unido, da Suécia, da Noruega, da Finlândia, da Dinamarca e da Holanda (GARTNER, 2012). Trata-se, então, de países com certa tradição na investigação em empreendedorismo. Tal fato repercute no desenvolvimento e na consolidação de correntes de pensamento particulares que delimitam a natureza e a lógica da produção científica nesses locais e demarcam a contribuição da produção originária desses países para o âmbito mais amplo da pesquisa sobre o referido fenômeno.

Do ponto de vista da cientometria e da bibliometria, verifica-se que os estudos sobre empreendedorismo começaram a tomar corpo acadêmico a partir da década de 1980 (MEYER, LIBAERS, THIJS et al., 2014), encontrando espaço para a divulgação em journals relevantes da área de Administração (MACMILLAN, 1993), embora com participação pequena em comparação à totalidade da produção sobre o tema (HARRISON e LEITCH, 1996). Nesse contexto, os primeiros esforços de revisão da produção científica em empreendedorismo surgiram entre o fim da década de 1980 e o início da década de 1990 (BUSENITZ, WEST, SHEPHERD et al., 2003). O mesmo pode ser dito sobre a produção francófona, que surge em meados dos anos 1980 e que começa a evoluir na década de 1990 (FAYOLLE, 2011; MARCHESNAY, 2011).

Busenitz, West, Shepherd et al. (2003), por meio de uma análise de 97 artigos publicados entre 1985 e 1999 em periódicos do campo da Administração, verificaram a emergência da área enquanto domínio particular de pesquisas, a partir do crescimento de estudos empíricos sobre o fenômeno e da base de conhecimento do campo. Os autores concluem que, para alcançar legitimidade enquanto campo próprio e independente, os pesquisadores devem buscar identificar as fronteiras daquilo que é empreendedorismo e desenvolver uma sólida base teórica, de modo a ampliá-la para além de seu estágio de emergência. 
Busenitz, Plummer, Klotz et al. (2014) retomam o estudo anterior (BUSENITZ, WEST, SHEPHERD et al., 2003) para comparar a evolução da pesquisa entre 1985 e 1999 e a publicação no período entre 2000 e 2009. No levantamento, identificaram-se 216 artigos sobre o tema divulgados em revistas de Administração e 644 textos publicados em periódicos especializados em empreendedorismo - Journal of Business Venturing e Entrepreneurship Theory and Practice. Os autores observaram que a pesquisa na área cresceu substancialmente ao longo das décadas de 1980, 1990 e 2000, apresentando interesse cada vez maior por temas como oportunidade de negócio e aspectos ambientais e contextuais do empreendedorismo. Além disso, os autores apontam que a área demonstra um aumento não apenas no volume de artigos publicados, mas também de seu impacto, a partir do crescimento de citações a esse conjunto de trabalhos, fato que sinaliza o crescimento da legitimidade do empreendedorismo como um campo de pesquisa.

Ferreira, Pinto e Miranda (2015) analisaram a estrutura da pesquisa em empreendedorismo, compreendendo 30 anos de publicações sobre o tema (1981-2010) em periódicos internacionais relevantes. O levantamento, ao oferecer um panorama de autores mais produtivos do campo e suas nacionalidades, das principais obras da literatura, do volume de citações, cocitações e principais temas pesquisados, identifica um padrão de crescimento da produção científica do campo, com a exploração de temáticas como: processo empreendedor; oportunidades; criação de valor/inovação e desempenho; características psicológicas, cognitivas e comportamentais dos empreendedores; e teorias, métodos e técnicas de pesquisa. Os autores concluem que a área se fundamenta em evidências de fenômenos empíricos, sendo, em certa medida, "ateórica". Assim, há a necessidade de estudos que ajudem a delimitar o domínio da pesquisa em empreendedorismo, com maior rigor e sofisticação metodológica.

Paralelamente, torna-se necessário particularizar o modo como a produção científica tem sido trabalhada em contextos regionais. Os estudos de Kizaba (2006), Blackburn e Smallbone (2008), Lasch e Yami (2008), Schmude, Welter e Heumann (2008), Ferreira, Santos, Reis et al. (2010), Nassif, Silva, Ono et al. (2010) e Oliveira Junior, Gattaz, Bernades et al. (2018) ajudaram a lançar luzes sobre essas diferentes realidades, problematizando temas de pesquisa, abordagens teórico-metodológicas e concentração de autoria e de instituições de pesquisa, bem como os processos de legitimação e institucionalização do campo de estudos nos países acima mencionados.

O estudo de Blackburn e Smallbone (2008), estruturado com o objetivo de mapear o desenvolvimento da pesquisa em empreendedorismo no Reino Unido, identificou algumas das características que distinguem a produção no referido país. $\mathrm{O}$ texto aponta um rápido crescimento do número de pesquisadores contribuindo com a área em um período de 30 anos, bem como suas crescentes legitimidade e institucionalização. A pesquisa no Reino Unido é marcada por uma rica diversidade de temas e abordagens, contemplando tópicos como a formação de políticas públicas ao empreendedorismo, o crescimento, o desenvolvimento e a sobrevivência de pequenos negócios, a figura do indivíduo empreendedor, a formação de redes e relacionamentos externos, a tecnologia, a globalização, a inovação e a propriedade intelectual, além da realização de estudos comparativos com outros contextos internacionais. Assim, podem ser destacados no campo de pesquisas britânico em empreendedorismo questões como uma forte tradição empírica, uma ampla diversidade metodológica, a ênfase em pequenas empresas e a configuração de um estágio pré-paradigmático e intermediário de desenvolvimento teórico do campo, compreendido entre uma teoria generalista e uma forte orientação a achados empíricos.

Por sua vez, o artigo de Schmude, Welter e Heumann (2008) foi elaborado com o intuito de revisar a literatura em empreendedorismo produzida na Alemanha, buscando identificar em que medida a pesquisa alemã se distingue e se diferencia daquela do mainstream (mais notadamente americano). O mapeamento possibilitou a constatação da emergência de um campo de estudos próprio a partir da década de 1990, em função do surgimento de cátedras de empreendedorismo em universidades alemãs e da primeira conferência anual sobre o tema. Os autores verificaram que a área é fortemente influenciada por suas raízes históricas, envolvendo uma tendência pela consideração de especificidades contextuais e pela multidisciplinaridade, dada a interação com a Escola Austríaca de inovação (incluindo Schumpeter) e com as concepções do indivíduo empreendedor e da influência do contexto social mais amplo, seguindo autores como Max Weber. Desse modo, a pesquisa germânica é marcada pela predominância de estudos sobre o contexto e a relação entre o empreendedorismo e o macroambiente (incluindo aí o papel do referido fenômeno e o desenvolvimento regional, setorial e econômico) influenciada pela escola schumpeteriana. Há também maior preocupação para com temáticas como o papel de universidades e a educação empreendedora, o capital de risco, as políticas públicas, o comportamento empreendedor e as características psicológicas de empreendedores (incluindo uma linha de investigações sobre diferenças entre empreendedores da Alemanha Ocidental e da Oriental) e empreendedorismo feminino. 
Ao lado desse contexto europeu, há também de se colocar a pesquisa e a produção científica brasileira em perspectiva. Nassif, Silva, Ono et al. (2010) apresentam um balanço retrospectivo da literatura brasileira em empreendedorismo, considerando as 127 comunicações do Encontro da Associação Nacional de Pós-graduação e Pesquisa em Administração (Enanpad), entre 2003 e 2008, e os 163 textos do Encontro de Estudos sobre Empreendedorismo e Gestão de Pequenas Empresas (Egepe), no período de 2000 a 2008. No âmbito dos 290 artigos analisados, houve a concentração da produção em torno de temas que relacionam comportamento, atitude, perfil e competências do empreendedor, sob uma ótica teórico-empírica. Já a revisão de Ferreira, Santos, Reis et al. (2010) buscou examinar o estado da arte da investigação sobre empreendedorismo no Brasil, através de 156 artigos publicados sobre o tema nos Enanpads ocorridos entre 1997 e 2008. Os resultados apontam que as comunicações foram elaboradas sob um amplo espectro de temas de interesse, com foco em questões contextuais, individuais e processuais. Constatou-se um crescimento do volume de publicações no período analisado, marcado por investigações empíricas e por estudos de caso.

Mais recentemente, Oliveira Junior, Gattaz, Bernades et al. (2018) realizaram uma revisão sistemática dos artigos sobre empreendedorismo publicados nas seis principais revistas brasileiras da área de Administração, durante o período 2000-2014. Entre as temáticas mais estudadas pelos pesquisadores, houve destaque para as investigações sobre o indivíduo empreendedor, o empreendedorismo social, as redes e o capital social, a orientação empreendedora, o empreendedorismo feminino e a educação empreendedora. No âmbito das abordagens metodológicas, verificou-se a prevalência de estudos de natureza qualitativa, fundamentados em entrevistas pessoais e estudos de caso. Os autores concluíram que o campo apresenta volume relativamente reduzido de produção científica nos principais periódicos nacionais. Tal fato demandaria a realização de estudos empíricos com maior rigor, a ampliação da base teórica existente e a criação de linhas de pesquisa sobre empreendedorismo nas instituições de ensino superior nacionais.

Por fim, cumpre destacar a produção em empreendedorismo no contexto francófono, objeto do presente artigo. Kizaba (2006) apresentou um balanço das revisões científicas e lançou luzes sobre dez anos da pesquisa francófona em empreendedorismo, descrevendo as características e tendências dos textos publicados entre os anos de 1995 e 2005 nos periódicos Revue Internationale $P M E$, Revue de l'Entrepreneuriat, Revue des Sciences de Gestion e Gestion 2000. O levantamento efetuado pelo autor identificou um total de 125 artigos, com destaque para temáticas associadas ao perfil e ao comportamento do empreendedor, à criação de organizações e ao processo empreendedor, à inovação e às estratégias de cooperação e internacionalização, à gestão de PMEs, às fontes de financiamento e fomento ao empreendedorismo, à aprendizagem e à educação empreendedora e ao papel do Estado. Kizaba (2006) concluiu que foi possível observar, no período analisado, a constituição de um campo de estudos particular, marcado por processos históricos de incubação, emergência, crescimento, institucionalização e objetificação, com reorientação de uma pesquisa fortemente influenciada por fontes acadêmicas internacionais para a delimitação de um "toque francês" de estudar empreendedorismo, com transições de focos de investigação sobre o indivíduo para o processo, do positivismo para o construtivismo, de estudos quantitativos para qualitativos, com forte preocupação, do ponto de vista empírico, com pequenos negócios e com a definição de posicionamentos científicos através da valorização de discussões de natureza epistemológica.

Lasch e Yami (2008), por sua vez, apresentaram uma visão geral das especificidades da pesquisa francófona em empreendedorismo. Segundo os autores, a emergência da produção científica sobre o tema data do período entre o fim da década de 1980 e o início dos anos 1990, com o crescimento significativo dessa produção observado após 1995 e o consequente aumento do reconhecimento e da legitimidade da área na França.

O mapeamento efetuado por Lasch e Yami (2008) identificou um total de 253 artigos, publicados entre 1996 e 2005 em dois periódicos do Canadá e da França respectivamente - Revue Internationale PME (RIPME) e Revue de l'Entrepreneuriat (RENT) - e em duas conferências acadêmicas internacionais da comunidade francófona - Conference Internationale Francophone en Entrepreneuriat et PME (CIFEPME) e Académie de l'Entrepreneuriat (AE). A revisão dessa literatura revelou uma predominância de estudos aplicados à realidade de PMEs, com ênfase em métodos qualitativos, e uma valorização de contribuições teórico-conceituais.

Além disso, o referido mapeamento identificou uma concentração da investigação em temáticas como o processo empreendedor (discutindo aspectos como o reconhecimento de oportunidades, a aquisição de recursos e as estratégias de negócio, entre outros) e os antecedentes do empreendedor (envolvendo questões como a origem, a personalidade, o comportamento e o processo de tomada de decisão), reunindo $40 \%$ do total de artigos publicados. No entanto, temáticas associadas ao empreendedorismo do ponto de vista organizacional (intraempreendedorismo, inovação etc.) e do ponto de vista ambiental 
(contexto, políticas públicas etc.) apareceram como tópicos emergentes na investigação. Esse conjunto de evidências aponta para uma distinção do positivismo empírico típico das pesquisas desenvolvidas sobre empreendedorismo nos Estados Unidos (LASCH e YAMI, 2008).

Não obstante, ao apreender as particularidades e as contribuições da produção científica francófona em empreendedorismo, torna-se necessário apresentar algumas considerações. Parece haver um consenso entre autores preocupados com a problematização do campo francófono de que a área é emergente, complexa e multifacetada, sendo marginalizada do ponto de vista internacional em função de barreiras culturais e de idioma e de seu estágio embrionário de legitimação e institucionalização (FAYOLLE, 2011, 2017; LASCH e YAMI, 2008; MARCHESNAY, 2008, 2011). Observa-se que os estudos têm sido influenciados, do ponto de vista conceitual, pela corrente processual norte-americana e pela corrente organizacional europeia, reverberando na configuração de artigos que valorizam elementos como o processo empreendedor e a concepção de oportunidades, o intraempreendedorismo e a inovação e as particularidades dos eventos de criação de negócios e os elementos idiossincráticos da gestão de PMEs (FAYOLLE, 2011; MARCHESNAY, 2008). Do ponto de vista conceitual, há dificuldades em se estabelecer definições sobre empreendedorismo e delimitar suas fronteiras, seu alcance e seus limites em uma perspectiva francófona, pois cultural e historicamente a França é marcada por várias heranças conflituosas, envolvendo disputas ideológicas influenciadas pela luta de classes e que questionam o status social do empreendedor, e por uma cultura organizacional baseada no gerencialismo e na burocracia (MARCHESNAY, 2008).

Assim, embora não exista uma delimitação conceitual totalmente distinta daquelas observadas em outras escolas de pensamento sobre o referido fenômeno, Fayolle (2011) aponta que a produção científica francófona tende a delimitar o empreendedorismo como um fenômeno baseado na ação, afastando-se em certa medida da vertente comportamental norte-americana e da vertente econômica germânica e diferenciando-se das concepções processuais norte-americanas nas delimitações epistemológica e metodológica. Nesse sentido, há uma ênfase em escolas interpretativistas, construcionistas, construtivistas e estruturalistas, além de foco na realização de investigações de natureza qualitativa e baseadas em estudos de caso em profundidade (KIZABA, 2006; MARCHESNAY, 2011). Desse modo, apesar da pertinência das ressalvas apontadas, verificam-se evidências que assinalam especificidades da produção francófona em termos de delimitação teórica e metodológica, que sugerem a demarcação de uma espécie de "toque francês" de se pesquisar empreendedorismo (FAYOLLE, 2017; MARCHESNAY, 2008; LASCH e YAMI, 2008).

Portanto, verifica-se que a evolução e as particularidades do campo oportunizam a elaboração de estudos revisionais que procurem mapear a literatura disponível sobre empreendedorismo em língua francesa, apontando para o escopo, a amplitude, o alcance e a profundidade dos estudos que abordam esse tema de pesquisas. Trata-se, pois, de responder ao questionamento ainda atual apresentado no trabalho seminal de Gartner (1990) - do que estamos falando quando falamos sobre empreendedorismo -, embora sob a ótica ou um toque francês (FAYOLLE, 2011; FAYOLLE, 2017; JULIEN e RAYMOND, 2008; LASCH e YAMI, 2008; MARCHESNAY, 2008; MARCHESNAY, 2011), recuperando 15 anos de produção científica francófona em empreendedorismo e adicionando novas evidências àquelas já destacadas nos levantamentos efetuados por Bizaka (2006) e por Lasch e Yami (2008). Mais ainda, busca-se apresentar esse debate para o campo de estudos em empreendedorismo no Brasil, de modo a visualizar possibilidades de novas pesquisas e de exploração de temáticas alternativas para a investigação sobre $o$ assunto.

\section{METODOLOGIA}

Nesta seção, explicitam-se os procedimentos metodológicos que nortearam o mapeamento efetuado no artigo. Para revisar a literatura francófona em empreendedorismo, buscou-se estruturar um levantamento da literatura disponível com base no método de revisão de escopo. Arksey e O'Malley (2005) definem que a revisão de escopo possui o objetivo de mapear os elementos centrais de um campo de pesquisas, examinando a extensão, o alcance e a natureza das publicações sobre um determinado tema. De acordo com Rumrill, Fitzgerald e Merchant (2010), tal procedimento oferece um roteiro para a realização de exercícios de revisão da literatura disponível sobre um tema de pesquisa. Assim, estabelece uma síntese que contribui para o entendimento das particularidades do campo científico em questão, viabilizando a identificação de padrões, tendências e lacunas da área, criando um panorama geral da agenda de estudos e orientando investigações futuras sobre uma dada temática. 
Com efeito, uma vez que existem diversas metodologias disponíveis para a realização de movimentos de revisão de literatura, torna-se necessário diferenciar a revisão de escopo de outras técnicas. Para Rumrill, Fitzgerald e Merchant (2010), a revisão de escopo surge como uma alternativa a métodos tradicionais de revisão: de um lado, a bibliometria seria voltada à quantificação e à análise estatística de tópicos teórico-metodológicos, relações de autoria e coautoria e de citação e cocitação, apresentando uma visão ampla da literatura, mas de forma relativamente superficial; e, de outro, as revisões sistemáticas levantam dados quantitativos sobre as evidências empíricas relacionadas a um dado tema de pesquisa e envolvem o emprego de técnicas estatísticas específicas para sumarizar, padronizar e melhor traduzir os resultados de investigação em dados agregados com a devida profundidade. Nesse sentido, a revisão de escopo seria uma espécie de meio termo entre as duas técnicas aqui destacadas, diferenciando-se ao apreender com densidade a amplitude de um tópico emergente de investigação por meio de uma metodologia rigorosa e transparente, embora seja limitada por não contemplar a síntese de evidências empíricas. Isso a posiciona, portanto, como uma revisão de natureza mais qualitativa e como uma etapa preliminar à realização de revisões sistemáticas sobre um determinado tema de pesquisas (ARKSEY e O'MALLEY, 2005).

Os estudos que empregam técnicas de revisão do escopo da literatura seguem um caminho preestabelecido, recorrendo a um roteiro para sua operacionalização (ZUPIC e CATER, 2015). Segundo autores como Arksey e O'Malley (2005) e Levac, Colquhuon e O'Brien (2010), a técnica de revisão de escopo da literatura compreende etapas como: a) definição da questão de pesquisa; b) identificação dos estudos relevantes para o campo a partir de refinamentos definidos pelos pesquisadores, delimitando-os de acordo com o tema, a fonte de publicação, o recorte temporal, os descritores e as palavras-chave, entre outros critérios; c) mapeamento, envolvendo a classificação e a categorização dos temas abordados, a natureza teórica, empírica e metodológica dos estudos e as questões de autoria, entre outras; e d) discussão e síntese dos resultados e/ou comparação com outras revisões. Desse modo, ao adotar essa técnica, seria possível identificar os padrões do campo de pesquisas, fornecendo-se reflexões pertinentes para o desenvolvimento de futuras investigações.

Neste trabalho, a operacionalização da metodologia de revisão de escopo envolveu a seguinte estrutura, inspirada no roteiro apresentado acima. Primeiramente, efetuou-se a definição do problema de pesquisa do mapeamento (quais as particularidades da produção científica em empreendedorismo publicada em língua francesa?). Com isso, foram mapeados artigos sobre empreendedorismo publicados em francês (delimitação do tema), compreendendo o período entre 2006 e 2019 (recorte temporal), imediatamente posterior ao analisado por Kizaba (2006) e Lasch e Yami (2008), para possibilitar uma avaliação do cenário do campo de estudos posterior a essas produções.

A partir disso, realizou-se a identificação dos artigos relevantes para o estudo. De início, estabeleceram-se critérios para a seleção dos periódicos e dos artigos a serem mapeados, a saber: a) critérios de inclusão - publicação de edições e números em frequência regular ao longo dos últimos 15 anos; presença de artigos científicos completos publicados no idioma francês; presença de trabalhos com temáticas especificamente associadas ao campo do empreendedorismo; periódicos com acesso aberto e/ou disponíveis no momento do levantamento; b) critérios de exclusão - publicação de edições e números em frequência irregular e/ou que não compreendiam a totalidade do recorte temporal indicado para o levantamento; periódicos com acesso restrito; periódicos baseados na França e no Canadá com publicação exclusiva de artigos em inglês; trabalhos de resenha bibliográfica, artigos convidados, comunicações editoriais e suas variantes; periódicos e artigos cujo foco central não corresponde à questão de pesquisa (artigos relacionados a temáticas correlatas exclusivamente, como a gestão de PMEs e de empresas familiares e a inovação, entre outras).

Com base na definição desses critérios de inclusão e exclusão, foram selecionados artigos publicados nos seguintes periódicos: a) Management International (MI), de caráter generalista na área de gestão, publicado pela HEC Montreal, considerada a primeira escola de negócios do Canadá; b) Revue Française de Gestion (RFG), de natureza generalista na área de gestão, criada em 1975 pela Fondation Nationale pour l'Enseignement de la Gestion des Entreprises (FNEGE) e publicada pela editora Lavoisier, sendo classificada como o principal periódico francês no campo da Administração pelo Comité National de la Recherche Scientifique (CNRS) e terceiro maior índice h5 dentre as revistas francófonas de todas as áreas segundo o Google Scholar; e c) Revue Internationale PME (RIPME), de caráter especializado na área do empreendedorismo e da gestão de pequenas empresas, criada em 1988, publicada pela Editions Management et Societé (EMS) e atualmente mantida em parceria pela AIREPME e pelo Institut de Recherche sur les PME da Université du Québec au Trois-Rivières - Canadá. Cumpre destacar que essas revistas são consideradas como meios de divulgação relevantes para a produção francófona sobre o fenômeno empreendedor (LASCH e YAMI, 2008; FAYOLLE, 2017), sobretudo por darem abertura editorial à temática - nos casos das revistas generalistas $M I$ e $R F G$ - e por terem relação com a associação científica voltada para o tema - no caso da RIPME 
(FAYOLLE, 2011, 2017; LASCH e YAMI, 2008; MARCHESNAY, 2008, 2011). Cumpre destacar que alguns periódicos francófonos generalistas e especializados com produção em empreendedorismo foram excluídos do levantamento em função dos critérios estabelecidos, como a Gestion 2000, a Revue des Sciences de Gestion, a Management Avenir, a Marché et Organization (acesso restrito) e a Revue de l'Entrepreneuriat (iniciada após 2001). Os dados agregados sobre os periódicos selecionados para a revisão de escopo são apresentados no Quadro 1:

\section{Quadro 1}

Dados agregados dos periódicos selecionados para a revisão de escopo

\begin{tabular}{|c|c|c|c|c|c|}
\hline Periódico & País & Indexadores & $\begin{array}{c}\text { Fator de Impacto } \\
\text { (SJR) }\end{array}$ & $\begin{array}{c}\text { Índice h5 } \\
\text { Google Scholar }\end{array}$ & $\begin{array}{c}\text { Ranking } \\
\text { CNRS/2019 }\end{array}$ \\
\hline $\begin{array}{c}\text { Management } \\
\text { International }\end{array}$ & Canadá & Érudit & Não possui & 10 & Categoria 2 \\
\hline $\begin{array}{c}\text { Revue Française } \\
\text { de Gestion }\end{array}$ & França & $\begin{array}{c}\text { Cairn, Ebsco, } \\
\text { Proquest, Scopus }\end{array}$ & 0,212 & 14 & Categoria 1 \\
\hline $\begin{array}{c}\text { Revue Internationale } \\
\text { PME. }\end{array}$ & Canadá & Érudit & Não possui & 6 & Categoria 3 \\
\hline
\end{tabular}

Fonte: Elaborado pelos autores.

Em seguida, efetuaram-se a identificação e a categorização dos artigos que fizeram parte desta revisão. Os textos foram analisados e organizados a partir de seus descritores, compreendendo elementos de identificação como seus títulos, resumos, palavras-chave e o conteúdo propriamente dito, o que permitiu uma classificação inicial dessa produção. Depois dessa etapa, procurou-se categorizar a produção, levando-se em consideração os tópicos a seguir: distribuição dos artigos entre os periódicos analisados; distribuição anual dos textos publicados; principais temas de pesquisa; tipo de abordagem dos artigos (ensaios teóricos, artigos teórico-empíricos, estudos revisionais); escolhas metodológicas; e principais autores do campo. Isso possibilitou mapear e contextualizar a produção francófona em empreendedorismo, apontando possíveis padrões, tendências e lacunas dessa produção, alcançando-se, assim, os objetivos propostos no presente levantamento. Por fim, cumpre ressaltar que o método para a classificação dos artigos foi inspirado nas contribuições das revisões de literatura desenvolvidas por Blackburn e Smallbone (2008), Julien e Raymond, (2008), Kizaba (2006), Lasch e Yami (2008), Marchesnay (2008), Oliveira Junior, Gattaz, Bernades et al. (2018) e Schmude, Welter e Heumann (2008).

\section{A produção científica francófona em empreendedorismo}

Conforme demonstrado, a literatura em empreendedorismo apresenta particularidades e características distintas, com uma multiplicidade de concepções, abordagens, quadros teóricos e métodos de investigação. A análise dessa literatura possibilita constatar a existência de algumas especificidades que são circunscritas à origem da publicação e/ou da pesquisa efetuada sobre o tema. Em tal cenário, diferentes autores realizaram esforços de revisão de literatura para compreender e explicar a natureza e a lógica de funcionamento do campo de estudos em empreendedorismo em seus diferentes países. Com base nessas iniciativas, procurou-se empregar o método de revisão de escopo de literatura no âmbito da produção francófona em empreendedorismo, considerando o período entre 2006 e 2019. Identificaram-se 166 artigos, publicados, conforme a distribuição a seguir (Tabela 1): 
Tabela 1

Distribuição da publicação francófona sobre empreendedorismo por periódico

\begin{tabular}{lccc}
\hline \multicolumn{1}{c}{ Periódico } & Nacionalidade & Total de artigos & $\%$ \\
\hline Management International (MI) & Canadá & 42 & 25,30 \\
Revue Française de Gestion (RFG) & França & 60 & 36,14 \\
Revue Internationale PME (RIPME) & Canadá & 64 & 38,56 \\
Total & & 166 & 100,00 \\
\hline
\end{tabular}

Fonte: Dados da pesquisa.

Nota-se, inicialmente, que as publicações sobre empreendedorismo estão nos meios de divulgação francófonos analisados. Cumpre destacar, nesse momento, a presença desses trabalhos em periódicos generalistas, casos do Management International (Canadá) e da Revue Française de Gestion (França). Esse dado, por si só, revela a abertura editorial dessas revistas para a exposição de artigos sobre empreendedorismo, fato nem sempre observado em periódicos tidos como representantes do mainstream acadêmico em gestão/negócios publicados em outros países, como vinha sendo o caso, por exemplo, dos Estados Unidos (MEYER, LIBAERS, THIJS et al., 2014). Apesar de ser generalista, nota-se que a Revue Française de Gestion, um dos principais periódicos científicos editados na França, apresentou praticamente o mesmo nível de publicação de uma revista especializada em empreendedorismo e gestão de pequenas empresas (Revue Internationale PME). Para fins de comparação, a média de publicações na RFG no período analisado foi de quatro artigos por ano. No levantamento efetuado por Kizaba (2006), a média de publicações na RFG entre 1995 e 2005 foi de, aproximadamente, 1 por ano. Isso ilustra a importância do volume dessa produção e a relevância dada à temática no contexto francófono, além de reforçar a constatação desse espaço editorial para a publicação de artigos sobre o referido fenômeno.

Outro aspecto que merece consideração refere-se à distribuição anual das publicações sobre o tema nos periódicos analisados (Tabela 2):

Tabela 2

Distribuição anual da publicação francófona sobre empreendedorismo

\begin{tabular}{ccccc}
\hline Ano & Management Intl. & Revue Française de Gestion & Revue Intl. PME & Total \\
\hline 2006 & 1 & 4 & 1 & 6 \\
2007 & 1 & 0 & 3 & 4 \\
2008 & 1 & 11 & 6 & 18 \\
2009 & 4 & 8 & 4 & 17 \\
2010 & 0 & 8 & 9 & 12 \\
2011 & 0 & 1 & 4 & 10 \\
2012 & 1 & 7 & 2 & 12 \\
2013 & 9 & 7 & 7 & 18 \\
2014 & 4 & 1 & 2 & 12 \\
2015 & 1 & 0 & 0 & 3 \\
2016 & 8 & 3 & 8 & 11 \\
2017 & 2 & 1 & 6 & 11 \\
2018 & 3 & 1 & 7 & 10 \\
2019 & 7 & 8 & 64 & 22 \\
Total & 42 & 60 & & 166 \\
\hline
\end{tabular}

Fonte: Dados da pesquisa. 
O mapeamento da distribuição anual da produção francófona em empreendedorismo revela alguns aspectos particulares. Por um lado, é possível constatar um aumento do interesse pelo tema, sobretudo entre os anos de 2008 e 2014. Esse incremento pode ser explicado, em parte, pela influência de chamadas especiais observadas, sobretudo, nas revistas generalistas, fato que incentiva os pesquisadores da área a divulgarem seus resultados de pesquisa ou proposições teóricas nos periódicos analisados. No total, realizaram-se oito chamadas especiais sobre empreendedorismo e subtemas relacionados, envolvendo questões como intraempreendedorismo, empreendedorismo setorial, perfil e comportamento empreendedor, empreendedorismo feminino, capital social, crowdfunding, fomento ao empreendedorismo e educação empreendedora. Nesse sentido, pode-se afirmar que existe um interesse importante desses periódicos e de suas equipes editoriais em abrir espaço e fomentar a divulgação de trabalhos sobre empreendedorismo, oportunizando a realização de estudos e pesquisas adicionais em empreendedorismo. Não obstante, com a diminuição do número de chamadas especiais sobre a temática, houve uma diminuição relativa da produção científica entre 2015 e 2018, com posterior retomada no ano de 2019.

Com base nesse cenário, a análise da evolução da produção científica francófona em empreendedorismo precisa ser melhor contextualizada e problematizada. Com efeito, práticas e discursos associados ao fenômeno empreendedor, sobretudo do ponto de vista econômico e social, têm sido cultural e historicamente questionados na França (FAYOLLE, 2011). De fato, Marchesnay (2008) aponta que a sociedade francesa tende a valorizar, em maior grau, a grande empresa gerencial, o que demonstra uma relativa dificuldade em abandonar o modelo fordista e um menosprezo com empresas de pequeno porte, consideradas como menos profissionais. Além disso, a França vinha sendo dominada, até a década de 1990, por valores e instituições hostis ao chamado "espírito empreendedor", como o catolicismo, o papel do Estado na economia e a importância e status dado a carreiras profissionais estáveis, como cargos públicos e em nível executivo provado. Nesse cenário, o capitalismo francês é comumente considerado como uma exceção, definido como um "capitalismo de Estado", uma mistura peculiar de estratégia corporativa com políticas públicas, sob a influência de uma "doxa gerencial" (MARCHESNAY, 2011). No entanto, entre o fim da década de 1980 até o fim dos anos 1990, verificou-se que eventos como a globalização, o desenvolvimento tecnológico e a intensificação das relações transacionais no nível da União Europeia modificaram valores da sociedade francesa, o que trouxe consigo tanto o aumento da legitimidade da figura do empreendedor no ambiento de negócios, no meio político e na mídia, quanto o aumento do interesse acadêmico por essa temática (MARCHESNAY, 2008).

Logo, em termos comparativos, nota-se que, nos estudos de Kizaba (2006) e Lasch e Yami (2008), a produção científica francófona entre 1995 e 2005 apresentava caráter de emergência, com aumento gradual de sua presença em periódicos generalistas e com o surgimento de periódicos especializados na temática. Já o período entre 2006 e 2019 revela exatamente a institucionalização dessa produção no âmbito das publicações analisadas. De fato, mesmo em um cenário marcado pela concorrência entre diversos tópicos de pesquisa, por pressões pela internacionalização de periódicos, com a publicação de textos em língua inglesa e com a inserção em bases de buscas como a Scopus, a Ebsco e a Web of Science, ainda se observou o aumento do volume de estudos produzidos e publicados sobre o tema. Isso reforça sua legitimidade e seu potencial no contexto acadêmico francês e canadense da área de gestão. Evidentemente, a manutenção desse crescimento e a consolidação da produção francófona em empreendedorismo passa, obrigatoriamente, pela necessidade de maior aprofundamento teórico-metodológico, por exercícios mais densos de problematização dos estudos e pelo aprimoramento das revisões de literatura, bem como pelo refinamento de métodos e técnicas de pesquisa, visando a uma melhoria dos níveis de rigor, confiabilidade e validade dessa produção científica (FAYOLLE, 2017).

Assim, corroborando com as discussões apresentadas nos estudos de Fayolle (2011), Lasch e Yami (2008), Marchesnay (2008), Marchesnay (2011) e Fayolle (2017), pode-se afirmar que o volume de produção científica mapeado sugere a formação de um campo de estudos francófono em empreendedorismo distinto. Ele contribui para a geração de evidências teórico-empíricas sobre o fenômeno empreendedor sob o ponto de vista francófono e para a disseminação desse conhecimento de origem francesa e canadense sobre empreendedorismo para níveis internacionais. Tal produção, em parte credora do aumento do interesse pelo tema observado ao longo dos últimos anos, colabora para a formação de um campo de estudos tão multifacetado quanto os campos de outros países. Contudo, é importante ressaltar que a produção francófona em empreendedorismo apresenta particularidades teórico-metodológicas relevantes em contraposição àquelas de origem norte-americana, inglesa, alemã e brasileira, requerendo mais profundidade e problematização desses aspectos distintivos e incluindo aí os seus diferentes temas de pesquisa e produção científica. Diante desse cenário, buscou-se categorizar a produção francófona com base nos temas de pesquisa mais explorados pelos investigadores da área (Tabela 3): 
Tabela 3

Temas de pesquisa explorados na produção francófona em empreendedorismo

\begin{tabular}{|c|c|c|c|}
\hline Tema & Artigos & Porcentagem & $\%$ Acumulada \\
\hline Intraempreendedorismo & 13 & 7,83 & 7,83 \\
\hline Fomento ao empreendedorismo & 12 & 7,23 & 15,06 \\
\hline Finanças & 12 & 7,23 & 22,29 \\
\hline Oportunidades & 12 & 7,23 & 29,52 \\
\hline Educação empreendedora & 10 & 6,02 & 35,54 \\
\hline Empreendedorismo feminino & 10 & 6,02 & 41,57 \\
\hline Intenção empreendedora & 10 & 6,02 & 47,59 \\
\hline Perfil e comportamento empreendedor & 9 & 5,42 & 53,01 \\
\hline Teoria e pesquisa em empreendedorismo & 7 & 4,22 & 57,23 \\
\hline Inovação & 7 & 4,22 & 61,45 \\
\hline Motivação ao empreendedorismo & 6 & 3,61 & 65,06 \\
\hline Capital social & 5 & 3,01 & 68,07 \\
\hline Criação de negócio & 5 & 3,01 & 71,08 \\
\hline Empreendedorismo na terceira idade & 5 & 3,01 & 74,10 \\
\hline Empreendedorismo social & 5 & 3,01 & 77,11 \\
\hline Empreendedorismo familiar & 4 & 2,41 & 79,52 \\
\hline Empreendedorismo institucional & 4 & 2,41 & 81,93 \\
\hline Empreendedorismo setorial (luxo) & 4 & 2,41 & 84,34 \\
\hline Empreendedorismo coletivo & 3 & 1,81 & 86,14 \\
\hline Empreendedorismo étnico & 3 & 1,81 & 87,95 \\
\hline Empreendedorismo rural & 3 & 1,81 & 89,76 \\
\hline Estratégia & 2 & 1,20 & 90,96 \\
\hline Ação empreendedora & 2 & 1,20 & 92,17 \\
\hline Aprendizagem & 2 & 1,20 & 93,37 \\
\hline Discurso sobre empreendedorismo & 2 & 1,20 & 94,58 \\
\hline Effectuation & 1 & 0,60 & 95,18 \\
\hline Empreendedorismo internacional & 1 & 0,60 & 95,78 \\
\hline Equipes empreendedoras & 1 & 0,60 & 96,39 \\
\hline Firmas empreendedoras & 1 & 0,60 & 96,99 \\
\hline Fracasso empreendedor & 1 & 0,60 & 97,59 \\
\hline Gestão de recursos humanos & 1 & 0,60 & 98,19 \\
\hline Orientação Empreendedora & 1 & 0,60 & 98,80 \\
\hline Redes & 1 & 0,60 & 99,40 \\
\hline Risco & 1 & 0,60 & 100,00 \\
\hline Total & 166 & 100,00 & 100,00 \\
\hline
\end{tabular}

Fonte: Dados da pesquisa.

O mapeamento dos temas de pesquisa explorados no âmbito da produção francófona em empreendedorismo permitiu algumas constatações importantes. Em especial, a identificação das temáticas expostas na Tabela 3 possibilitou a observação de alguns padrões, os quais se organizam em termos de tópicos investigados e de concentração da produção, e de temáticas pouco exploradas na área, que revelam lacunas e/ou temáticas inexploradas em comparação à literatura internacional (sobretudo de origem inglesa). 
Identificaram-se 34 diferentes tópicos de investigação trabalhados pelos pesquisadores da área. Entre aqueles que mais se destacam e, de certa maneira, concentram parte significativa da produção científica sobre a temática no âmbito dos periódicos analisados, nota-se a predominância de temas como: a) intraempreendedorismo, contemplando suas diferentes variações, como empreendedorismo organizacional e empreendedorismo corporativo etc., e analisando sua manifestação no contexto de organizações privadas de pequeno e médio portes, a partir de perspectivas como inovação, criatividade e criação de valor; b) o fomento ao empreendedorismo, incluindo tópicos como a atuação de agências de fomento e a construção de políticas públicas em diferentes contextos regionais e nacionais; c) as finanças, com a problematização de temáticas como venture capital, fontes de financiamento de novos negócios e inovações e crowdfunding, entre outros; e d) a concepção de oportunidades, envolvendo elementos como os processos de criação e/ou identificação e exploração de oportunidades, alerta empreendedor etc. Além desses tópicos, temas como educação empreendedora, empreendedorismo feminino, intenção empreendedora, perfil e comportamento empreendedor e discussões sobre teoria e pesquisa em empreendedorismo também apresentam volume relevante de produção científica nos periódicos analisados.

Neste momento, cumpre destacar que as temáticas acima mencionadas concentram, em conjunto, $78,03 \%$ de toda a produção científica em empreendedorismo em língua francesa. Trata-se, pois, da caracterização de um rol de temas de pesquisa que formam um padrão e um conjunto mais amplo de tendências de investigação na área, direcionando tanto a geração de conhecimento sobre empreendedorismo na França e no Canadá quanto a reunião de esforços de autores interessados em problematizar a natureza e a lógica de manifestação do fenômeno empreendedor. Ao se configurar sob tal perspectiva, esse padrão e essa tendência da pesquisa e da produção científica contribuem, potencialmente, para a constituição de uma agenda de pesquisas francófona sobre empreendedorismo. Isso permite a problematização de aspectos vinculados a fatores que podem ser compreendidos e analisados, ao mesmo tempo, do ponto de vista teórico e do ponto de vista empírico, incluindo-se uma série de contextos organizacionais, setoriais, regionais e nacionais. Adicionalmente, a identificação dessa agenda de pesquisas sobre o tema oportuniza a publicação de estudos (inclusive brasileiros) que investiguem essas temáticas e divulguem seus achados nesses periódicos, reforçando o potencial de exploração desses espaços para a divulgação de estudos sobre empreendedorismo.

Por outro lado, verifica-se que determinadas temáticas têm sido pouco exploradas pelos pesquisadores. Existem lacunas a serem preenchidas, envolvendo a necessidade de trabalhos que explorem perspectivas como a relação entre empreendedorismo e empresas familiares, geralmente analisadas sob a ótica do empreendedorismo familiar, a relação entre empreendedorismo e inovação, a relação entre empreendedorismo e estratégia, a concepção de orientação empreendedora, o conceito de effectuation, a noção de processo empreendedor, a relação entre empreendedorismo e redes e/ou franquias e a abordagem do empreendedorismo quanto a minorias ou especificidades regionais/nacionais, como os empreendedorismos étnico, feminino, racial, rural, setorial, regional e/ou nacional, podem contribuir para a ampliação dos conhecimentos existentes sobre esse tema e para o avanço do campo. Com base nessa discussão, torna-se necessário problematizar o tipo de pesquisa que tem sido publicado no contexto francófono da produção sobre empreendedorismo (Tabela 4):

Tabela 4

Tipo de pesquisa na produção científica francófona em empreendedorismo

\begin{tabular}{lcccc}
\hline \multicolumn{1}{c}{ Tipo de Pesquisa } & $\begin{array}{c}\text { Management } \\
\text { International }\end{array}$ & $\begin{array}{c}\text { Revue Française } \\
\text { de Gestion }\end{array}$ & $\begin{array}{c}\text { Revue } \\
\text { Internationale PME }\end{array}$ & Total \\
\hline Teórico-conceitual & 9 & 21 & 10 & 40 \\
Teórico-empírico & 32 & 39 & 48 & 119 \\
Revisão de literatura & 1 & 0 & 6 & 7 \\
Total & 42 & 60 & 64 & 166 \\
\hline
\end{tabular}

Fonte: Dados da pesquisa.

Embora a predominância de estudos de natureza teórico-empírica seja um resultado relativamente previsível, encontrado com frequência em outros trabalhos de mapeamento da literatura disponível em diferentes áreas do conhecimento (ZUPIC e CATER, 2015), alguns aspectos merecem consideração. Ao colocar em perspectiva a origem dessa produção, verifica-se que há prevalência de estudos teórico-empíricos no âmbito da RIPME (75\% do total de artigos publicados), o que pode 
denotar um perfil editorial específico de tal revista no sentido de priorizar e valorizar esse tipo de produção. Por outro lado, a RFG apresenta maior abertura a trabalhos de natureza teórica (35\% do total), fato que sugere maior abertura do referido periódico para a discussão conceitual sobre empreendedorismo, contribuindo em grau relevante para o desenvolvimento do campo de pesquisas sobre o tema. Além disso, a RIPME, em maior grau, e a MI, em menor grau, abrem espaço para a publicação de revisões de literatura acerca de temáticas associadas ao empreendedorismo, envolvendo desde formulações mais amplas sobre a construção do campo de estudos relacionadas ao fenômeno empreendedor no contexto francês, canadense e até mesmo alemão, bem como problematizações mais específicas sobre elementos como o comportamento empreendedor, as finanças empreendedoras, o empreendedorismo social e a orientação empreendedora. Nesse sentido, observa-se que esses dados fornecem pistas a pesquisadores interessados a publicar seus estudos e resultados de pesquisa conceitual e/ou teórico-empírica em meios de divulgação francófonos, pois possibilitam otimização e melhor adequação da submissão de trabalhos junto a periódicos que apresentem maior aderência a seus artigos.

Com o tipo de pesquisa, há a necessidade, também, de se considerar os métodos de pesquisa empregados nos artigos (Tabela 5):

Tabela 5

Métodos de pesquisa utilizados na produção francófona em empreendedorismo

\begin{tabular}{lcccc}
\hline \multicolumn{1}{c}{ Método } & MI & RFG & RIPME & Total \\
\hline Ensaio teórico & 9 & 21 & 10 & 40 \\
Qualitativo & 20 & 28 & 26 & 74 \\
Quantitativo & 12 & 11 & 18 & 41 \\
Multimétodo & 0 & 0 & 4 & 4 \\
Revisão de literatura & 1 & 0 & 6 & 7 \\
Total & 42 & 60 & 64 & 166 \\
\hline
\end{tabular}

Fonte: Dados da pesquisa.

Os dados demonstram uma predominância da abordagem qualitativa de investigação (44,6\% do total), fato que apresenta um interessante paralelo com a realidade observada no campo de pesquisas e produção científica no Brasil (OLIVEIRA JUNIOR, GATTAZ, BERNADES et al., 2018). Outro destaque diferenciador do campo francófono, em comparação à produção científica sobre empreendedorismo desenvolvida em outros países, pode ser observado na importância atribuída a trabalhos de natureza teórico-conceituais ( $28,3 \%$ do total), um movimento que contribui não só para a própria problematização da área, mas também para a geração de conhecimentos contextualizados à realidade desse campo. Assim, cabe ressaltar que tais resultados se mostram distintos daquele observado em outras revisões de literatura, mais notadamente aquelas que problematizam a produção científica em países de influência maior do positivismo sobre as ciências sociais e ciências sociais aplicadas (BUSENITZ, PLUMMER, KLOTZ et al., 2014; BLACKBURN e SMALLBONE, 2008; SCHMUDE, WELTER e HEUMANN, 2008). Por um lado, verificou-se que esses trabalhos de natureza qualitativa foram desenvolvidos em torno de fundamentos interpretativistas, construcionistas, construtivistas e estruturalistas, tendo sido certamente influenciados por uma tradição mais ampla do ambiente acadêmico francófono, sobretudo de origem francesa. Isso reflete na qualidade das discussões efetuadas, em termos de profundidade e densidade, e na geração de um conhecimento específico mais contextualizado e circunscrito às realidades investigadas, algo que diferencia esse campo particular de estudos. Por outro lado, esses mesmos trabalhos, ao serem desenvolvidos, em sua maioria, sob a ótica de estudos de caso ou multicasos, apresentam uma certa limitação em relação ao alcance dos resultados dessas pesquisas, quando não abordados do ponto de vista de desenvolvimento teórico. Tal crítica também pode ser constatada nas revisões de Bizaka (2006), Fayolle (2017), Julien e Raymond (2008), Lasch e Yami (2008) e Marchesnay (2008). Além disso, verifica-se a realização de poucos estudos que efetuam triangulação entre métodos, estratégias e técnicas de pesquisa ( $2,4 \%$ do total), fato que, se por um lado constitui uma limitação da produção francófona, por outro revela uma oportunidade para a realização de estudos com maior densidade e potencial de contribuir para a área.

Outro aspecto importante desse mapeamento consiste na possibilidade de identificar os autores considerados referências para a produção francófona em empreendedorismo, que possuem origem em diversos países da comunidade de língua francesa e revelam uma interessante pluralidade acadêmica (Tabela 6): 
Tabela 6

Autores proeminentes da produção francófona em empreendedorismo

\begin{tabular}{lc}
\hline \multicolumn{1}{c}{ Autor } & Qtde \\
\hline Alain Fayolle & 12 \\
Didier Chabaud & 5 \\
Émile-Michel & \\
Hernandez & 5 \\
Frank Janssen & 5 \\
Michel Marchesnay & 5 \\
Éric-Alain Zoukoua & 4 \\
Isabelle Calme & 4 \\
Karim Messeghem & 4 \\
Olivier Giacomin & 4 \\
Stéphane Onnée & 4 \\
Camille Carrier & 3 \\
Cécile Fonrouge & 3 \\
Jean-Pierre Boissin & 3 \\
Josée St-Pierre & 3 \\
Maripier Tremblay & 3 \\
Nazik Fadil & 3 \\
Olivier Basso & 3 \\
Véronique Bouchard & 3 \\
Louis Jacques Filion & 2 \\
Louise Cadieux & 2 \\
Lucie Bégin & 3 \\
Pierre-André Julien & 3 \\
\hline Thierry Verstraete & 3 \\
\hline Fonte: Dados & 3 \\
\hline
\end{tabular}

Fonte: Dados da pesquisa.

Identificou-se, no conjunto dos 166 artigos analisados, um total de 383 autores, perfazendo uma média de 2,3 autores por trabalho, o que sugere um grau relevante de colaboração acadêmica para a produção de conhecimento sobre o tema. De modo específico, nota-se a predominância de autores de origem francesa e canadense, lotados em sua maioria em cátedras de universidades daqueles países. Isso demonstra que a produção francófona é original e gerada, em sua maioria, em laboratórios e instituições de ensino e pesquisa desses países. Autores baseados na França (como Alain Fayolle, Didier Chabaud, Émile-Michel Hernandez e Michel Marchesnay), no Canadá (como Camillie Carrier, Maripier Tremblay, Louis Jacques Filion e Pierre-André Julien) e na Bélgica (como Frank Janssen), entre tantos outros, produzem parte relevante da literatura francófona na área, contribuindo para o desenvolvimento do campo e estabelecendo temas de pesquisa, métodos de investigação e agendas de estudo relevantes para a área. No entanto, merece destaque a baixa presença de pesquisadores brasileiros (4 de 383 autores de trabalhos) no rol de autores de artigos francófonos, fato que, embora reflita uma limitação em termos de internacionalização da pesquisa brasileira, pode oportunizar a divulgação de estudos contextualizados à realidade do empreendedorismo no Brasil no âmbito desses periódicos. 


\section{CONSIDERAÇÕES FINAIS}

O presente artigo objetivou revisar a literatura em empreendedorismo publicada em língua francesa em periódicos baseados na França e no Canadá. Para tanto, foi efetuado um levantamento dos artigos divulgados nos periódicos Management International, Revue Française de Gestion e Revue Internationale PME com base no método de revisão de escopo da literatura, o que permitiu a identificação e a categorização de um total de 166 artigos publicados sobre a temática no período entre 2006 e 2019.

Pode-se afirmar que o conjunto de evidências aqui identificado revela a constituição de um campo de pesquisas francófono em empreendedorismo. O campo é marcado por particularidades que ora o posicionam em consonância com outros contextos nacionais - como o rigor conceitual, observado em estudos dos Estados Unidos e da Inglaterra, ou a valorização de metodologias qualitativas, percebida no Brasil - ora de forma diferenciada quanto a outros contextos (como na elaboração de ensaios que contribuem para o desenvolvimento teórico da área e na exploração de temáticas pouco trabalhadas em outros países, incluindo-se questões étnicas, raciais, setoriais, contextuais, individuais, sociais e de gênero). Assim, forma-se um quadro amplo e multifacetado que muito tem a contribuir em termos de evidências teóricas e empíricas para os estudos sobre empreendedorismo em uma perspectiva global e, evidentemente, em uma perspectiva brasileira.

Com isso, verificam-se múltiplas vertentes da produção e da disseminação de conhecimento em empreendedorismo no âmbito da literatura francófona. Em termos comparativos, percebe-se que a produção francófona em empreendedorismo difere, em parte, daquela observada em países como os Estados Unidos (com ênfase em aspectos comportamentais e processuais), a Inglaterra (com ênfase em aspectos organizacionais) e a Alemanha (com ênfase em aspectos inovativos e setoriais). Com efeito, diversos autores que procuraram problematizar a dinâmica do campo de estudos sobre o fenômeno empreendedor nos âmbitos francês e canadense ressaltam a influência das escolas norte-americanas e britânicas na emergência desse campo de estudos. No entanto, o movimento observado a partir de meados da década de 1990 até o ano de 2005 consolidou-se nos anos seguintes, tendo os autores se preocupado com questões como o desenvolvimento teórico do campo e a problematização de tópicos mais amplos da pesquisa sobre o tema, incluindo o processo empreendedor e a noção de oportunidades, a criação de organizações, o intraempreendedorismo e a inovação, bem como a manifestação do fenômeno empreendedor em situações e objetos especificamente relevantes no contexto francófono. Tal fato permitiu não só a consolidação da área naquele cenário acadêmico, mas também particularizando e diferenciando sua contribuição em termos internacionais.

Com isso, depreende-se que a produção francófona em empreendedorismo apresenta possibilidades e alternativas teórico-metodológicas para a realização de estudos e investigações sobre o fenômeno empreendedor, o qual, pelo menos em parte, se aproxima daquilo que é pesquisado, produzido e publicado no Brasil. Como consequência, acredita-se que autores brasileiros interessados em publicar trabalhos sobre empreendedorismo possam, em princípio, encontrar um espaço para a divulgação de seus artigos nos periódicos francófonos. Esse espaço surge, certamente, como uma alternativa e oportunidade para a internacionalização dos resultados de investigações realizadas no Brasil sobre o referido tema e para a própria difusão internacional do campo de pesquisas em empreendedorismo no país, fato que ainda não é observado de forma efetiva em periódicos de língua inglesa.

Como não poderia deixar de ser, este estudo demonstra algumas limitações. Primeiro, o conjunto de periódicos analisados, embora represente parte relevante dos meios de divulgação disponíveis para a produção científica em empreendedorismo, não contempla a totalidade do cenário de publicações francófonas sobre o fenômeno empreendedor, conforme explicitado na seção metodológica deste trabalho. Estudos futuros podem explorar outros periódicos da área de administração ou de empreendedorismo e gestão de pequenas empresas, ampliando o número de revistas analisadas ou, até mesmo, replicando o quadro de periódicos analisados em outros levantamentos, para fins de comparação. Segundo, o recorte temporal analisado, embora relevante, permite contemplar apenas parcialmente essa produção científica. Conforme indicado, tal mapeamento procurou adicionar novas evidências àquelas identificadas nos estudos apresentados por Bizaka (2006) e por Lasch e Yami (2008). No entanto, a revisão de escopo foi efetuada com base em periódicos e recortes temporais distintos, devido às dificuldades de acesso também mencionadas na metodologia. No entanto, a presente revisão lança luz sobre um mesmo contexto de evidências identificadas por esses autores, reforçando e avançando nas constatações apresentadas por esses autores. Estudos futuros poderiam explorar um recorte temporal mais amplo e/ou adicionar novas revistas ao levantamento, para acessar de modo mais compreensivo e abrangente a referida produção. Terceiro, apesar de o presente estudo apresentar classificações e identificar categorias consistentes com outras revisões da mesma natureza, não foi possível explorar outros 
aspectos pertinentes. Sugere-se que novos trabalhos explorem tópicos diferenciados, como as principais abordagens teóricas, ontológicas e epistemológicas da pesquisa, as principais referências e citações/cocitações, os principais conceitos operacionalizados, a estrutura de definição conceitual do termo empreendedorismo na escola francófona e possíveis diferenças desta em relação a outras escolas de pensamento, como a norte-americana e a brasileira, as redes de autoria e as relações institucionais regionais, nacionais e internacionais.

Não obstante, apesar dessas limitações, este estudo contribui ao colocar a pesquisa e a produção científica francófona em empreendedorismo em perspectiva, revelando possibilidades, alternativas e caminhos teórico-metodológicos para a realização de estudos e investigações sobre o fenômeno empreendedor. Há, nesse sentido, oportunidades para diálogos e trocas entre o campo de estudos sobre empreendedorismo no Brasil e a literatura francófona, incluindo a exploração, em pesquisas brasileiras, de temáticas recorrentes nos âmbitos francês e canadense, e a publicação de estudos brasileiros (sobretudo qualitativos) nos periódicos mapeados, divulgando os olhares teóricos e os contextos empíricos nacionais aos leitores em língua francesa. Trata-se, portanto, de contribuir para a identificação de evidências que contribuam para a consolidação da área e, mais precisamente, para a constatação daquilo que, afinal, estamos falando quando falamos sobre empreendedorismo em francês. 


\section{REFERÊNCIAS}

ALVAREZ, S. A.; BARNEY, J. B. Entrepreneurship and epistemology: the philosophical underpinnings of the study of entrepreneurial opportunities. Academy of Management Annals, v. 4, n. 1, p. 557583, 2010.

ARKSEY, H.; O'MALLEY, L. Scoping studies: towards a methodological framework. International Journal of Social Research Methodology, v. 8, n. 1, p. 19-32, 2005.

BLACKBURN, R. A.; SMALLBONE, D. Researching small firms and entrepreneurship in the U.K.: developments and distinctiveness. Entrepreneurship Theory and Practice, v. 32, n. 2, p. 267-288, 2008.

BUSENITZ, L. W. et al. Entrepreneurship research in emergence: past trends and future directions. Journal of Management, v. 29, n. 3, p. 285-308, 2003.

BUSENITZ. L. W. et al. Entrepreneurship research (1985-2009) and the emergence of opportunities. Entrepreneurship Theory and Practice, v. 38, n. 5, p. 981-1000, 2014.

CARLSSON, B. et al. The evolving domain of entrepreneurship research. Small Business Economics, v. 41, n. 4, p. 913-930, 2013.

CLARK, C. M.; HARISSON, C. Entrepreneurship: an assimilated multiperspective review. Journal of Small Business \& Management, v. 31, n. 1, p. 43-71, 2019.

FAYOLLE, A. Entrepreneurship and small business research in Frenchspeaking countries: an introduction. Journal of Small Business and Enterprise Development, v. 18, n. 2, p. 1-4, 2011.

FAYOLLE, A. Thinking the future of entrepreneurship research through French lenses. Revue Internationale des Sciences de L'Organisation, v. 2, n. 3, p. 59-72, 2017.

FAYOLLE, A. What we know and what we need to know in the field of entrepreneurship. In: FAYOLLE, A. (Ed.). Handbook of Entrepreneurship Research: what we know and what we need to know. Cheltenham: E. Elgar, 2014. p. 1-12.

FERREIRA, M. P. et al. Entrepreneurship research: a bibliometric study of Enanpads 1997-2008. Revista Brasileira de Estratégia, v. 3, n. 1, p. 31-47, 2010.

FERREIRA, M. P. V.; PINTO, C. F.; MIRANDA, R. M. Três décadas de pesquisa em empreendedorismo: uma revisão dos principais periódicos internacionais de empreendedorismo. Revista Eletrônica de Administração, v. 21, n. 2, p. 406-436, 2015.

FILION, L. J. Empreendedorismo: empreendedores e proprietáriosgerentes de pequenos negócios. Revista de Administração, v. 34, n. 2, p 5-28, 1999.

GARTNER, W. B. Entrepreneurship as organization creation. In: HJORTH, D. (Org.). Handbook on Organisational Entrepreneurship. Cheltenham: E. Elgar, 2012. p. 21-30.

GARTNER, W. B. What are we talking about when we talk about entrepreneurship? Journal of Business Venturing, v. 5, n. 1, p. 15-28, 1990.

GARTNER, W. B.; BRUSH, C. G. Entrepreneurship as organizing: emergence, newness, and transformation. In: GARTNER, W. B.
(Org.). Entrepreneurship as Organizing: selected papers of Willian B. Gartner. Cheltenham: E. Elgar, 2016. p. 291-310.

HARRISON, R.; LEITCH, C. Discipline emergence in entrepreneurship: accumulative fragmentalism or paradigmatic science. Entrepreneurship: Innovation \& Change, v. 5, n. 2, p. 65-83, 1996.

HJORTH, D. Sketching a philosophy of entrepreneurship. In: BAKER, T.; WELTER, F. (Eds.). The Routledge Companion to Entrepreneurship. New York: Routledge, 2015. p. 41-58.

JULIEN, P.-A.; RAYMOND, L. Vingt ans de recherche francophone en PME et entrepreneuriat. Revue Internationale PME, v. 21, n. 2, p. 7-8, 2008.

KIZABA, G. Revues scientifiques et 10 ans de recherche francophone en entrepreneuriat. Innovations, v. 24, n. 2, p. 231-258, 2006.

LASCH, F.; YAMI, S. The nature and focus of entrepreneurship research in France over the last decade: a French touch? Entrepreneurship Theory and Practice, v. 32, n. 2, p. 339-360, 2008.

LEVAC, D.; COLQUHUON, H.; O'BRIEN, K. K. Scoping studies: advancing the methodology. Implementation Science, v. 5, n. 69, p. 1-9, 2010.

LOPES, R. M. A.; LIMA, E. Desafios atuais e para a pesquisa em empreendedorismo. Revista de Administração de Empresas, v. 59, n. 4, p. 284-292, 2019.

MACMILLAN, I. C. The emerging forum of entrepreneurship scholars. Journal of Business Venturing, v. 8, n. 5, p. 377-381, 1993.

MARCHESNAY, M. Trente ans d'entrepreneuriat et PME en France: naissance, connaissance, reconnaissance. Revue Internationale PME, v. 21, n. 2, p. 145-168, 2008.

MARCHESNAY, M. Fifty years of entrepreneurship and SME: a personal view. Journal of Small Business and Enterprise Development, v. 18, n. 2, p. 352-365, 2011.

MCDONALD, S. et al. A review of research methods in entrepreneurship 1985-2013. International Journal of Entrepreneurial Behavior \& Research, v. 21, n. 3, p. 291-315, 2015.

MEYER, M. et al. Origins and emergence of entrepreneurship as a research field. Scientometrics, v. 98, n. 1, p. 473-485, 2014.

NASSIF, V. M. J. et al. Empreendedorismo: área em evolução? Uma revisão dos estudos e artigos publicados entre 2000 e 2008. Revista de Administração e Inovação, v. 7, n. 1, p. 175-192, 2010.

OLIVEIRA JUNIOR, A. B. et al. Pesquisa em empreendedorismo (20002014) nas seis principais revistas brasileiras de administração: lacunas e direcionamentos. Cadernos EBAPE.BR, v. 16, n. 4, p. 610-630, 2018.

RUMRILL, P. D.; FITZGERALD, S. M.; MERCHANT, W. R. Using scoping literature reviews as a means of understanding and interpreting existing literature. Work, v. 35, n. 3, p. 399-404, 2010.

SCHMUDE, J.; WELTER, F.; HEUMANN, S. Entrepreneurship research in Germany. Entrepreneurship Theory and Practice, v. 32, n. 2, p. 289-311, 2008.

SHANE, S.; VENKATARAMAN, S. The promise of entrepreneurship as a field of research. Academy of Management Review, v. 25, n. 1, p. 217-226, 2000. 
SHEPHERD, D. A. et al. What are we explaining? A review and agenda on initiating, performing, and contextualizing Entrepreneurship. Journal of Management, v. 45, n. 1, p. 159-196, 2019.

TEIXEIRA, A. A. C. Mapping the (in)visible college(s) in the field of entrepreneurship. Scientometrics, v. 89, n. 1, p. 1-36, 2011.

TURCAN, R. V.; FRASER, N. M. Multi-disciplinary perspectives on entrepreneurship. In: TURCAN, R. V.; FRASER, N. M. (Eds.). The Palgrave Handbook of Multidisciplinary Perspectives on Entrepreneurship. Cham, Switzerland: Palgrave MacMillan, 2018. p. 3-13.
VALE, G. M. V. Empreendedor: origens, concepções teóricas, dispersão e integração. Revista de Administração Contemporânea, v. 18, n. 6, p. 874-891, 2014.

WIKLUND, J.; WRIGHT, M.; ZAHRA, S. A. Conquering relevance: entrepreneurship research's grand challenge. Entrepreneurship Theory and Practice, v. 43, n. 3, p. 419-436, 2019.

ZUPIC, I.; CATER, T. Bibliometric methods in management and organization. Organizational Research Methods, v. 18, n. 3, p. 429472, 2015.

Alex Fernando Borges

ORCID: https://orcid.org/0000-0001-7269-5196

Doutor em Administração pela Universidade Federal de Lavras (UFLA); Professor Adjunto na Universidade Federal de Uberlândia (UFU), Ituiutaba MG, Brasil. E-mail: alexborges@ufu.br

Alessandro Gomes Enoque ORCID: https://orcid.org/0000-0002-1766-0684

Doutor em Sociologia e Ciência Política pela Universidade Federal de Minas Gerais (UFMG); Professor Associado na Universidade Federal de Uberlândia (UFU), Ituiutaba - MG, Brasil. E-mail: alessandroenoque@ufu.br 